\title{
Fire-Resistant Pits: Reducing the Probability of Accidental Plutonium Dispersal from Fuel Fires
}

\author{
Douglas R. Stephens
}

March 1992

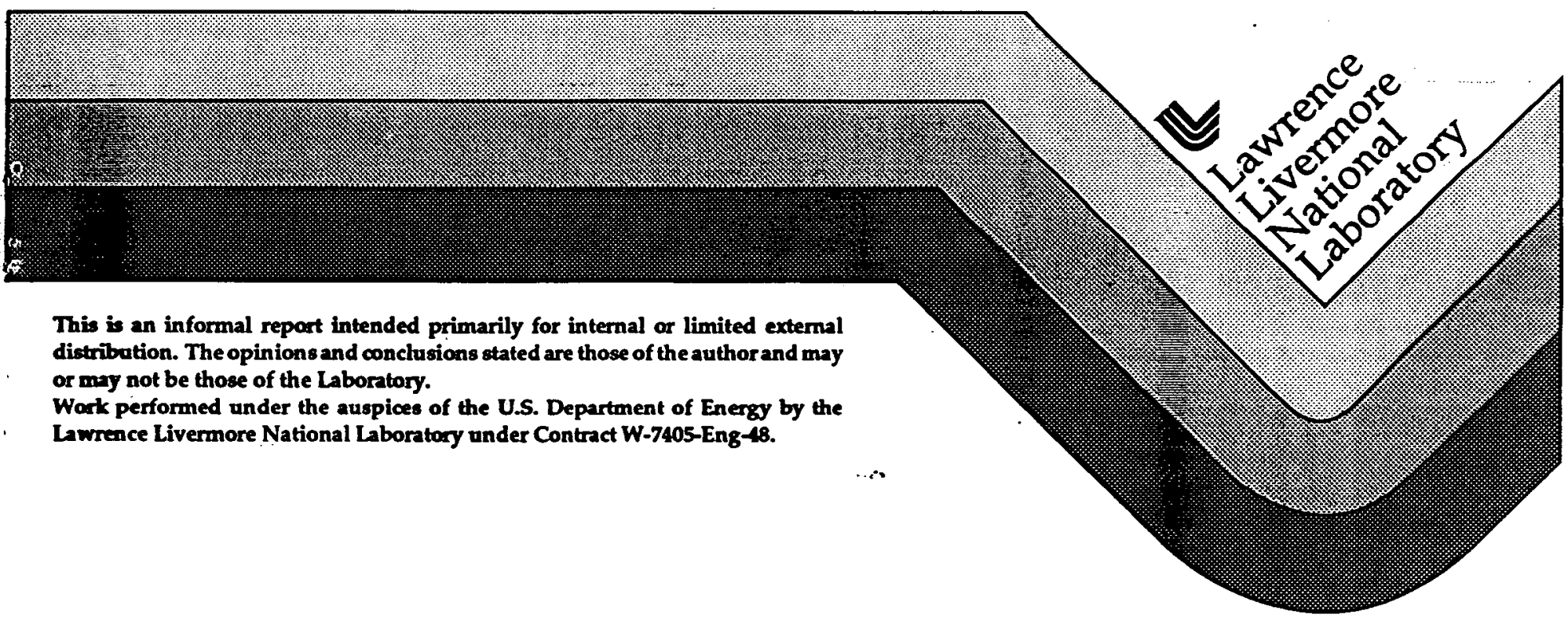




\section{DISCLAIMER}

This report was prepared as an account of work sponsored by an agency of the United States Government. Neither the United States Government nor any agency Thereof, nor any of their employees, makes any warranty, express or implied, or assumes any legal liability or responsibility for the accuracy, completeness, or usefulness of any information, apparatus, product, or process disclosed, or represents that its use would not infringe privately owned rights. Reference herein to any specific commercial product, process, or service by trade name, trademark, manufacturer, or otherwise does not necessarily constitute or imply its endorsement, recommendation, or favoring by the United States Government or any agency thereof. The views and opinions of authors expressed herein do not necessarily state or reflect those of the United States Government or any agency thereof. 


\section{DISCLAIMER}

Portions of this document may be illegible in electronic image products. Images are produced from the best available original document. 


\section{Fire-Resistant Pits: Reducing the Probability of Accidental Plutonium Dispersal from Fuel Fires}

Douglas R. Stephens

March 1992

\section{ABSTRACT}

Reductions in risk of $\mathrm{Pu}$ dispersal from hydrocarbon fuel fires were estimated using pool and spill fire data. Improvements in FRP temperature capabilities, on a system-independent basis, lead to the following estimated reductions in risk, using three probabilistic temperature distributions normalized to a temperature capability of $640^{\circ} \mathrm{C}$ (the melting point of plutonium):

$$
\begin{aligned}
& 1000^{\circ} \mathrm{C} \text { - factor of } 3 \text { to } 5 \\
& 1100^{\circ} \mathrm{C} \text { - factor of } 10 \text { to } 13 \\
& 1200^{\circ} \mathrm{C} \text { - factor of } 120 \text { to } 300
\end{aligned}
$$

The above values would, of course, vary for a different normalization temperature. These values were derived to be as system-independent as possible. Incorporation of fuel fire durations or of longer time-averaging (than the two minutes employed in this study) would tend to increase these FRP improvement factors. Incorporation of propellant fires, burning metal or of combined impact/fire accidents would tend to decrease them.

Further studies of fuel fire durations, particularly of a fuel fire duration model, is recommended, as is an uncertainty analysis of the temperature distributions. 


\section{INTRODUCTION}

The safety and control of U.S. nuclear weapons have always been of paramount importance. Areas of concern include the prevention of nuclear detonation and of plutonium dispersal by fire or by nonnuclear detonation of the weapon's high explosive (HE). A number of innovative design features have improved the safety, security, and control of U.S. deployed nuclear weapons, including weaklink/stronglink designs, insensitive high explosives (IHE), and fireresistant pit designs.

The risks of plutonium dispersal by $\mathrm{HE}$ detonation have been assessed. 1-10 The development and use of IHE in modern weapon designs virtually eliminates the possibility of accidental HE detonation, except for the possibilities of detonation of nearby propellant or certain extreme multiple events (such as fragmentation and/or heat followed by impact).

Although the use of IHE has virtually eliminated the probability of plutonium release by accidental detonation, the risk of plutonium release in the event of fire remains. The accident scenarios of concern are those in which nuclear weapons are involved in a hydrocarbon fuel fire of such intensity and duration as to breach the pit and thereby disperse the plutonium due to combustion followed by the entrainment of the plutonium oxide particles into the fire plume. This risk led LLNL to design nuclear weapons that can withstand typical fuel fire temperatures and durations.

Efforts in both materials science and device design are underway to increase the temperature and time that a fire-resistant pit (FRP) can withstand in order to lessen even further the possibility of the release of special nuclear material due to fire. Weapons introduced into the stockpile with both IHE and FRPs include the B83, W84, and the W87. The W89, now in Phase 4, will also contain IHE and FRP. Some assessments of the risks $\mathrm{Pu}$ release by fire have been carried out.7-9, 11, 12

\section{Plutonium Release Criteria and Methodology}

The fire resistance of a nuclear weapon results from its ability to withstand both impact and high temperature for times up to several hours. Plutonium release can occur from an undamaged weapon when the fire temperature and/or fire duration exceed the system's capability. Or, an accident involving a violent impact (e.g., an airplane crash) may rupture the pit, thereby destroying its fire resistance, and a subsequent fire may disperse the plutonium. The probability of an object in a fire experiencing high temperature decreases with increasing temperature, and the 
probability of a fire burning for a given duration decreases with increasing time (i.e., the extremely high-temperature and/or long-duration fires are relatively rare).

FRP technology reduces the probability of plutonium release by fire, over that of systems without FRP, but by how much? The best approach to answer this question is to carry out a probabilistic risk assessment (PRA) for each weapon, for each and every weapon state. A good example of this methodology is given by the DOE Pilot Study12 and the W89 PRA.13 Such a PRA requires a time scale of up to two years and costs of several million dollars.

Point-probabilistic risk assessments have been carried out for the SRAM-A system $^{8}$ and for transportation ${ }^{9}$ These studies can be carried out in less than 1 year for about $\$ 0.5-1 \mathrm{M}$.

A simplified accident event sequence is shown in Figure 1. Accident scenarios, as typically portrayed in event trees, lead to accident environments which, when imposed on a warhead, lead to weapon environments. These in turn lead to weapon response, which, if greater than the Pu threshold dispersal function, leads to Pu dispersal and resulting consequences, which can be expressed as human health effects, cleanup areas, and total accident costs.

An example accident scenario, that of an aircraft crash into an alert strategic bomber, is also shown in the figure.

These types of analyses lead to estimates of frequency of Pu release $\mathrm{F}$ and consequences $C$, and in turn to risk $R$,

$$
\mathrm{R}=\mathrm{F} \times \mathrm{C}
$$

Life-cycle risks for a nuclear warhead include all potential accidents from its assembly at Pantex, transportation from Pantex to the weapon's operational site (which can include one or more intermediate destinations), intermediate storage, operations at the site (including unloading, storage, maintenance, mating to delivery systems, etc.) any other logistical movements of the weapon, and finally its transportation back to Pantex and disassembly at the end of its operational life.

We next discuss relative risk, i.e., that of one weapon to another. For example, for a given accident scenario $F=F_{A}$ PAE PWE P(Pu dispersal/WE) 


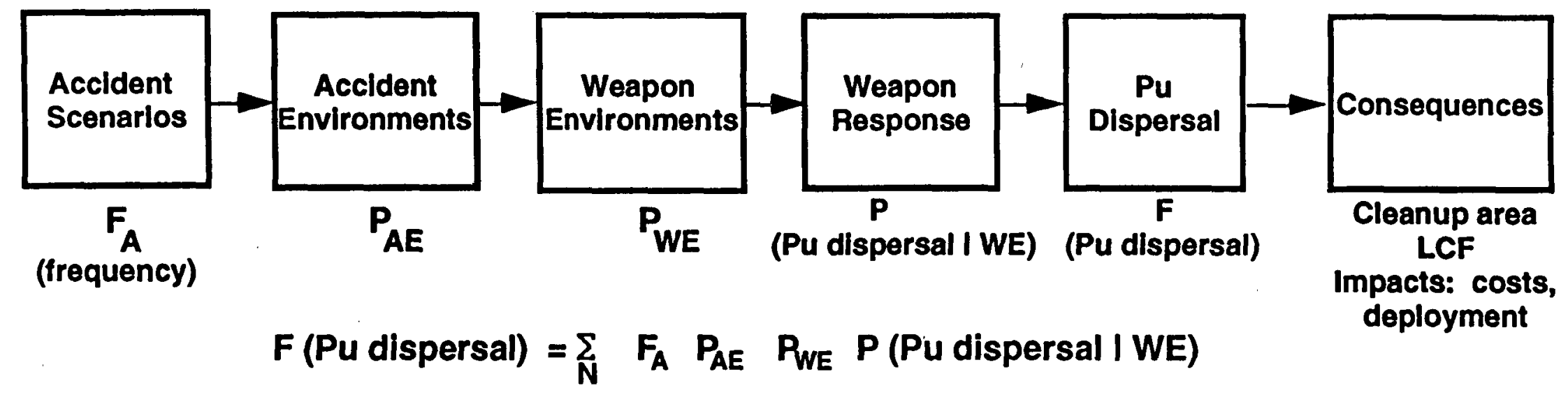

Example: Aircraft crashes Into an alert bomber

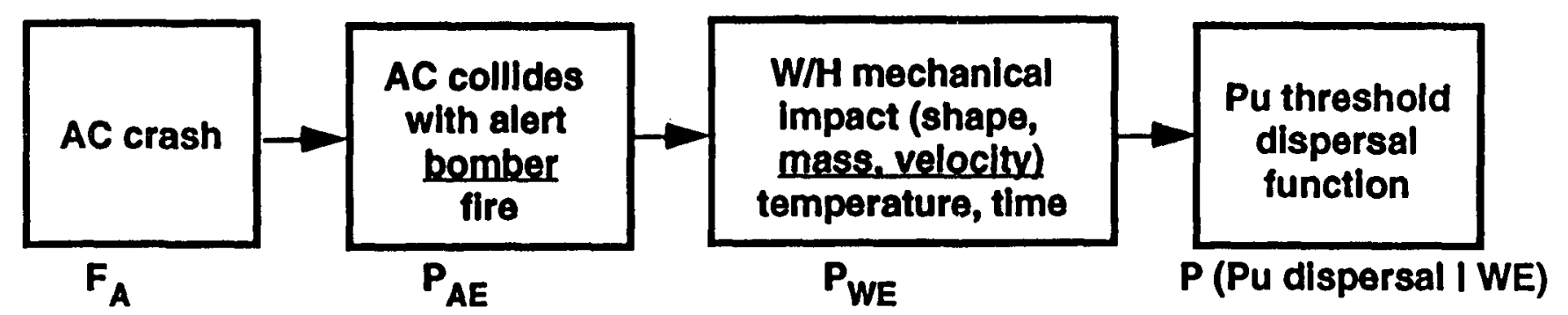

Figure 1: Accident Event Sequence 
where

$\mathrm{F} \quad=$ frequency of Pu dispersal

$F_{A}=$ frequency of accident

PAE = conditional probability of accident environment of a given severity, given the accident

PWE = conditional probability of a weapon environment of a given severity, given the accident environment

$\mathrm{P}(\mathrm{Pu}$ dispersal/WE $)=$ conditional probability of $\mathrm{Pu}$ dispersal given the weapon environment

for

$$
\begin{aligned}
& \mathrm{FA}=\text { constant } \\
& \text { PAE }=\text { constant } \\
& \text { PWE }=\text { constant }
\end{aligned}
$$

then

$$
\text { Relative } \mathrm{Pu} \text { release frequency }=\frac{F_{1}}{F_{2}}=\frac{P\left(P u \text { dispersal } / W E_{1}\right)}{P(P u \text { dispersal/WE2 })}
$$

In this case we compare the relative Pu release frequency of two weapons by the ratios of their conditional $\mathrm{Pu}$ release probabilities, given a weapon environment.

\section{Fuel Fire Temperature and Duration}

The conditional probability of plutonium dispersal, given a fuel fire is:

$P(P u$ dispersal | fire $)=\int_{t} \int_{T>H_{P u}(t)} f_{f}(t) P_{t}(T) d T d t$

where

$f_{f}(t)=$ fire duration density function

$p_{f}(T)=$ fire temperature density function

$\mathrm{HPu}(\mathrm{t})=\mathrm{Pu}$ dispersal threshold function

For a given accident scenario and $f f(t)=$ constant, the relative $P u$ release probability of WH1 to WH2, $\mathrm{PR}_{\mathrm{R}}$, is:

$$
P_{R}=\frac{P_{f}\left(T_{1}\right)}{P_{f}\left(T_{2}\right)} \quad \begin{aligned}
& T_{1}=\text { temperature capability of Pit } 1 \\
& T_{2}=\text { temperature capability of Pit } 2
\end{aligned}
$$


The reciprocal of the relative $\mathrm{Pu}$ release probability $\mathrm{PR}$ is defined as the improvement factor IF (or risk reduction factor) which, for a pit 1 relative to a pit 2, is:

$$
\text { IF }=\frac{1}{P_{R}}=\frac{P_{f}\left(T_{2}\right)}{P_{f}\left(T_{1}\right)}
$$

These types of comparisons can be rather insensitive to system-specific issues.

We will use these relative Pu release probabilities to estimate the relaiive safety improvements provided by FRPs of differing fire resistance. To do this we next examine probabilistic temperature distributions in hydrocarbon fuel fires. These are obtained from two basic sets of data; those for large pool fires and from spill fires.

\section{Pool Fires}

Possible temperature magnitudes and variations in aircraft fuel fires are estimated in this section from data on large pool fires: experimental laboratory fuel fires with area dimensions up to $9 \times 18 \mathrm{~m}$.

Large pool fire temperatures are highly non-uniform in both space and time, due to wind effects, turbulence, and both radiant and convective heat losses. The fuel-air ratios and mixing are far from uniform within the fire.

Maximum temperatures generally are found at the centerline of the pool and 1-3 $\mathrm{m}$ above the burning pool surface, depending upon the size of the pool and wind conditions. Reference 14 states "the range from 927 to $1260^{\circ} \mathrm{C}$ is typical of the luminous plume engulfment region of large pool fires."

It may be mentioned here that typical large pool fires are sooty, and therefore optically opaque, with an extinction coefficient of about $1 / \mathrm{m}$. 15 Thus a small body within a large pool fire cannot "see" the ambient conditions and will reach the flame temperature given sufficient time.

In an earlier study Clarke et.al. 16 derived a probabilistic model for aircraft fuel (JP-4) flame temperatures, assuming an average (or typical) fuel fire temperature of $1010^{\circ} \mathrm{C}\left(1850^{\circ} \mathrm{F}\right)$ and a $95 \%$ upper limit of $1315^{\circ} \mathrm{C}\left(2400^{\circ} \mathrm{F}\right)$.

However, these considerations do not completely apply to the case of nuclear weapon fire safety. Although peak temperatures of $1300^{\circ} \mathrm{C}$ or so are observed in 
very limited volumes in fuel fires, duration of these maxima are for a few seconds, as shown in Figure 215 and are not significant for the heating and subsequent attack of bodies with finite thermal inertia. Inspection of fuel fire data show peak sustainable temperatures of $1200^{\circ} \mathrm{C}$ or less.

Although $1200^{\circ} \mathrm{C}$ appears to be a reasonable upper limit for JP-4 or JP-5 fuel fires, it must be noted that an aircraft fire temperature can be raised by burning of aluminum or other metal alloys. Whether these are actual temperatures imposed upon a warhead are difficult to estimate. But, in some cases some locations in an aircraft fire may exceed $1200^{\circ} \mathrm{C}$.

The extensive data from eleven large free-field JP-4 and JP-5 pool fires allow an examination of temperature variations with time and space.15,17-20 The experimenters used fixed grids of 50 thermocouples or more within the volume of the fire, and thus temperatures averaged over time and volume can be computed.

Inspection of the data show that the average temperature is less than $1000^{\circ} \mathrm{C}$. Radioactive heat losses tend to decrease the temperature if the heated object partially "sees out" of the fire environment.

I employed time-averaging of two minutes as a reasonable time constant for a bare pit. The sensitivity to time constants of 1-5 minutes is not believed to be a large effect. 21,22

The values in Table 1 were derived for time-and-volume-average temperature probabilities, using two-minute averaging, and based upon eleven large hydrocarbon fuel pool fires. 11 There is an equal probability that an object is within any volume element of the fire.

\section{Spill Fires}

Free-field spill fire temperature distributions are based on nine large hydrocarbon fuel (JP-4) spill fires, taken for wind speeds of 5-25 mph and spill rates of 150-600 gpm. 23. The experimental design is shown schematically in Fig.3.

These spill fires exhibit phenomenology similar to that previously described for pool fires but in addition provide information about wind effects. Maximum temperatures decrease with increasing wind speed, but the maximum temperature is closer to the ground. Typical data are shown in Fig.4.

Two-minute averaging was employed by Mansfield 24 to derive the probabilistic temperature distributions shown in Table 2. The distributions are 


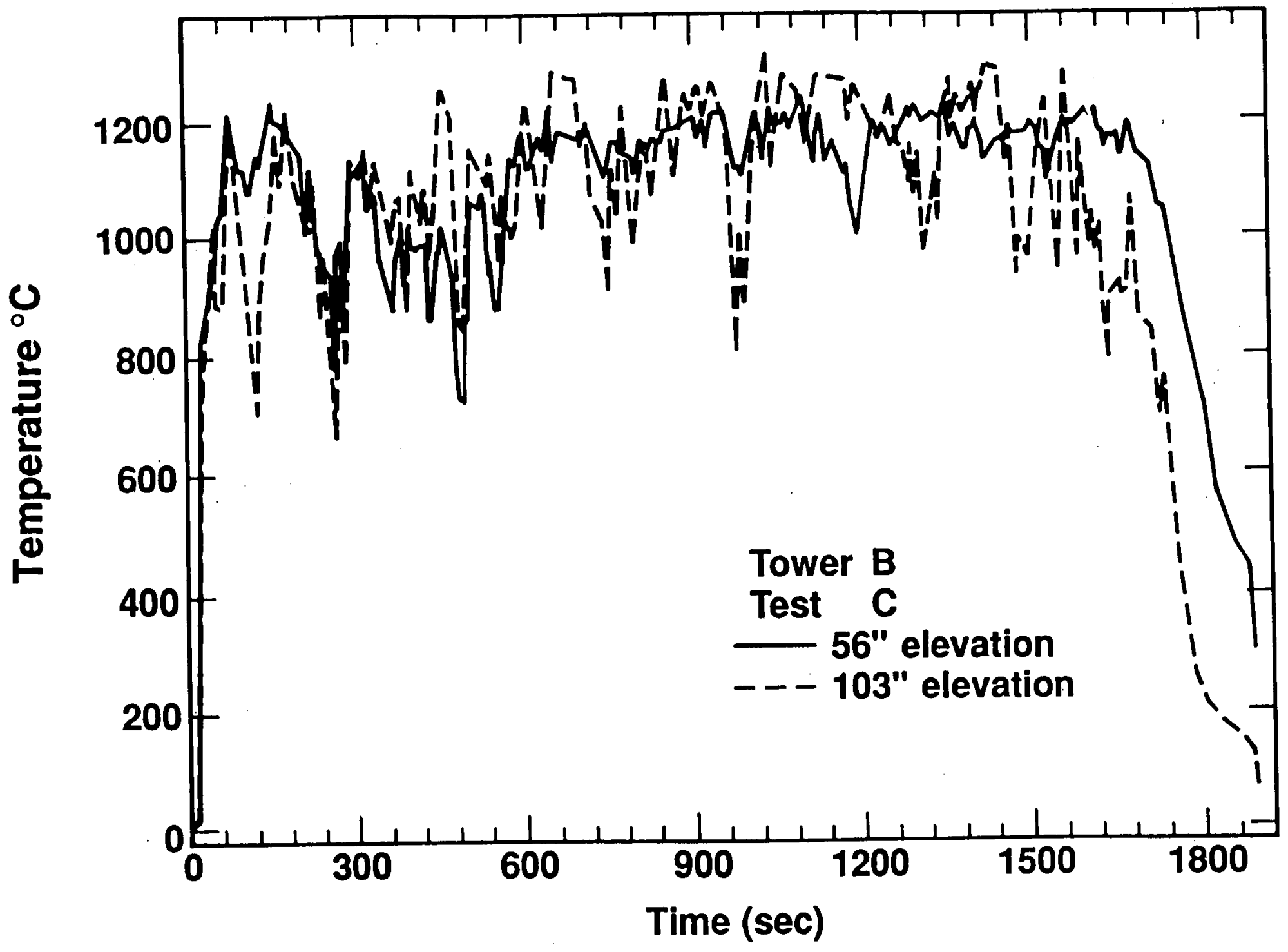

Figure 2: Temperature variations in large pool fire Source: Gregory et al, SAND 85-0196 
Table 1. Probabilistic temperature distributions from eleven large pool fires: two-minute averaging

\begin{tabular}{|c|c|}
\hline Temperature & $\mathrm{P}(\mathrm{T}>\mathrm{T})$ \\
\hline 640 & 1.00 \\
\hline 700 & 0.976 \\
\hline 800 & 0.889 \\
\hline 900 & 0.700 \\
\hline 1000 & 0.370 \\
\hline 1100 & 0.08 \\
\hline 1200 & 0.005 \\
\hline
\end{tabular}




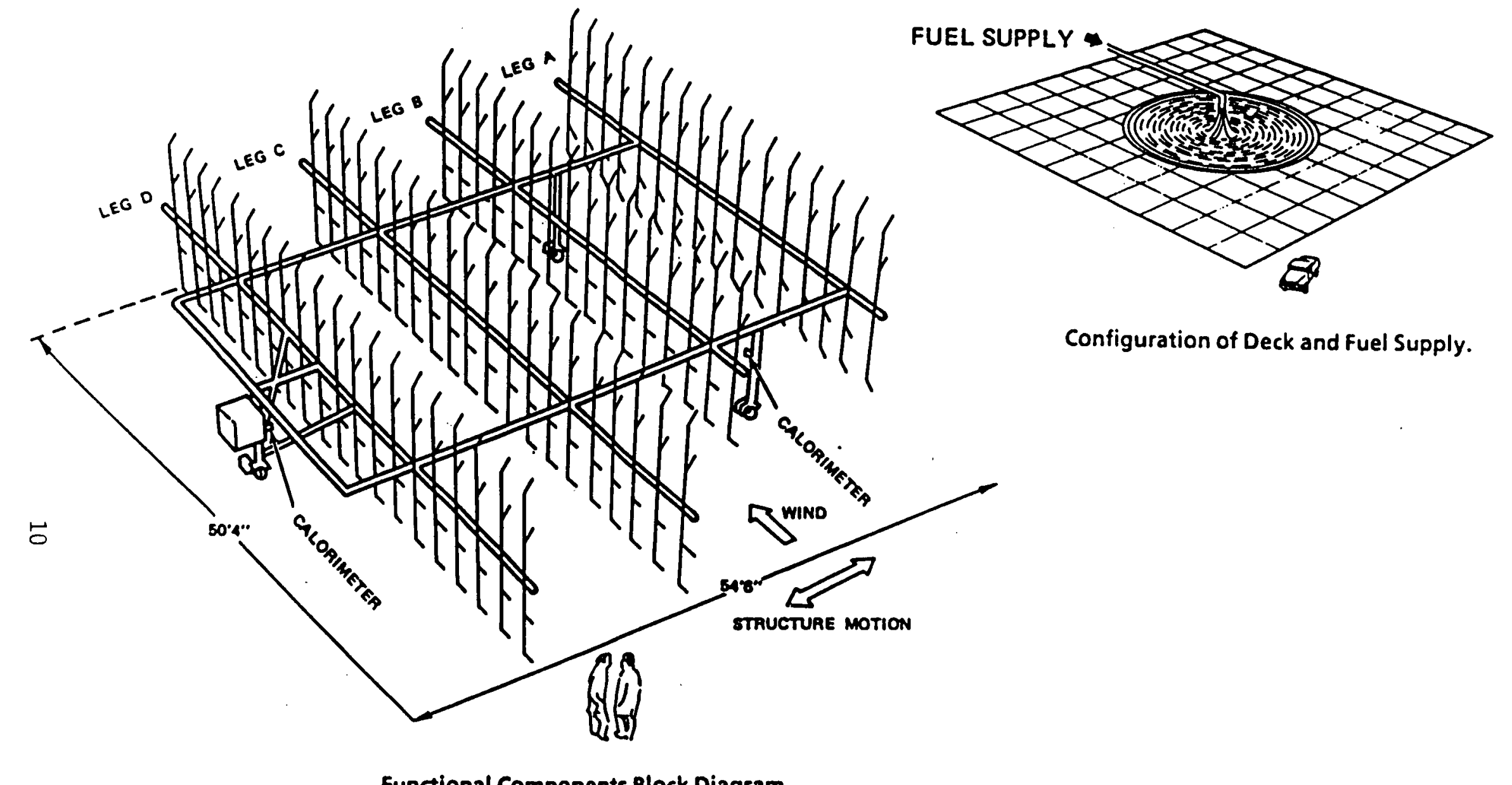

Functional Components Block Diagram.

Figure 3: Spill fire experimental design 


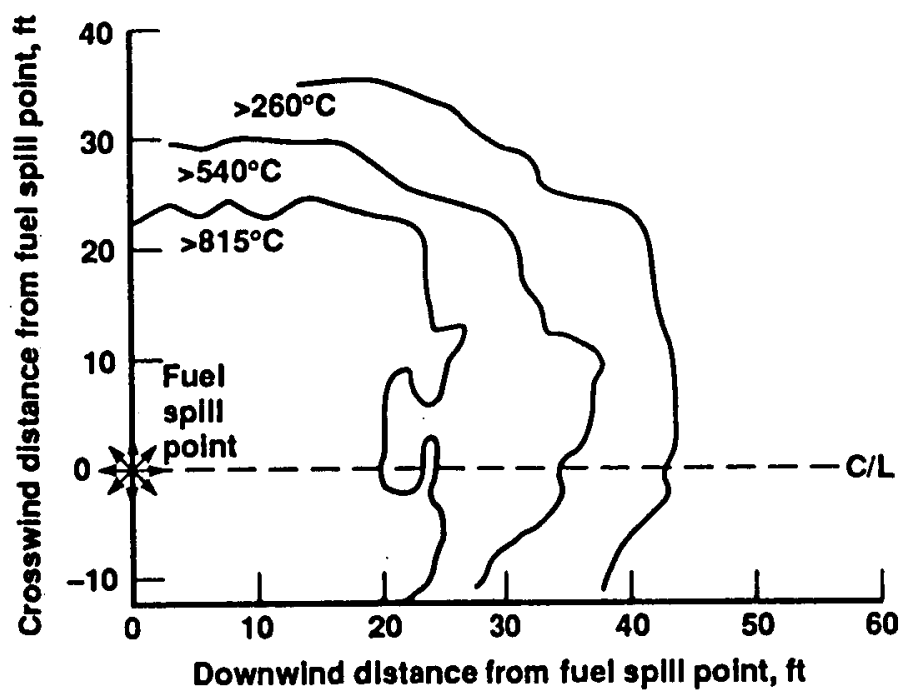

(a) 1-Foot height

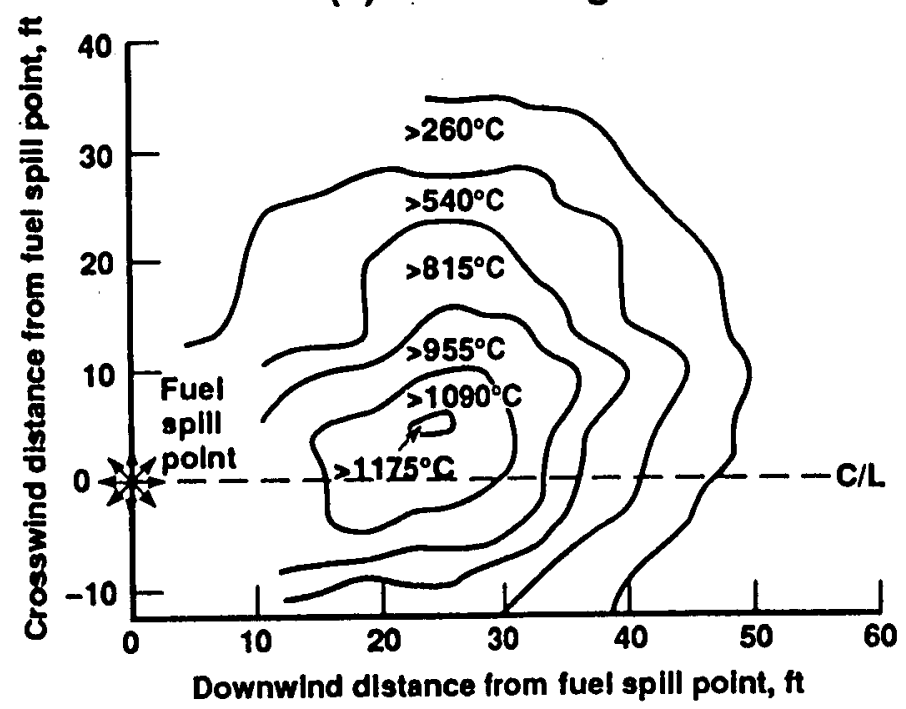

(c) 7-Foot height

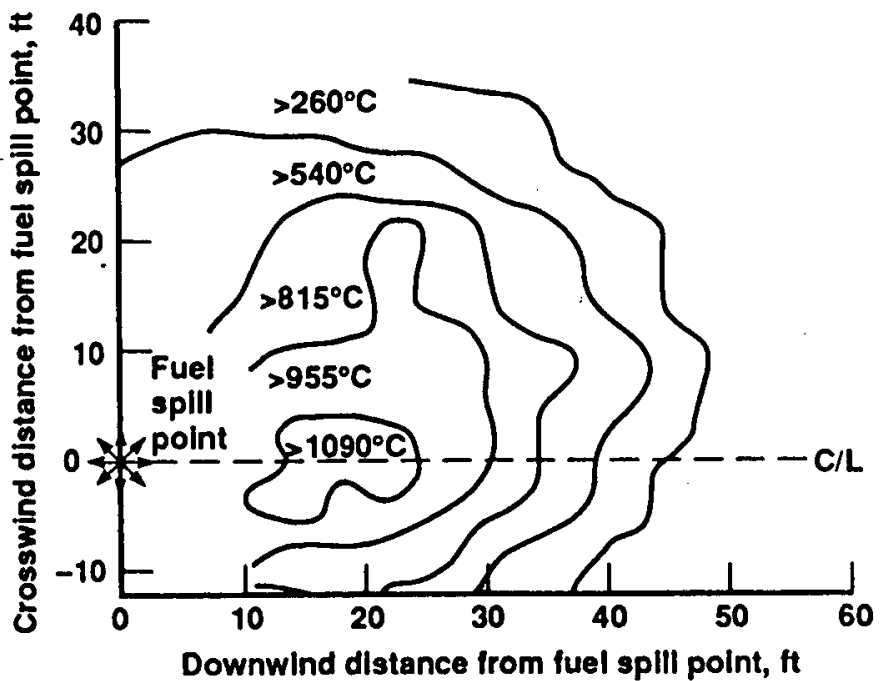

(b) 4-Foot height

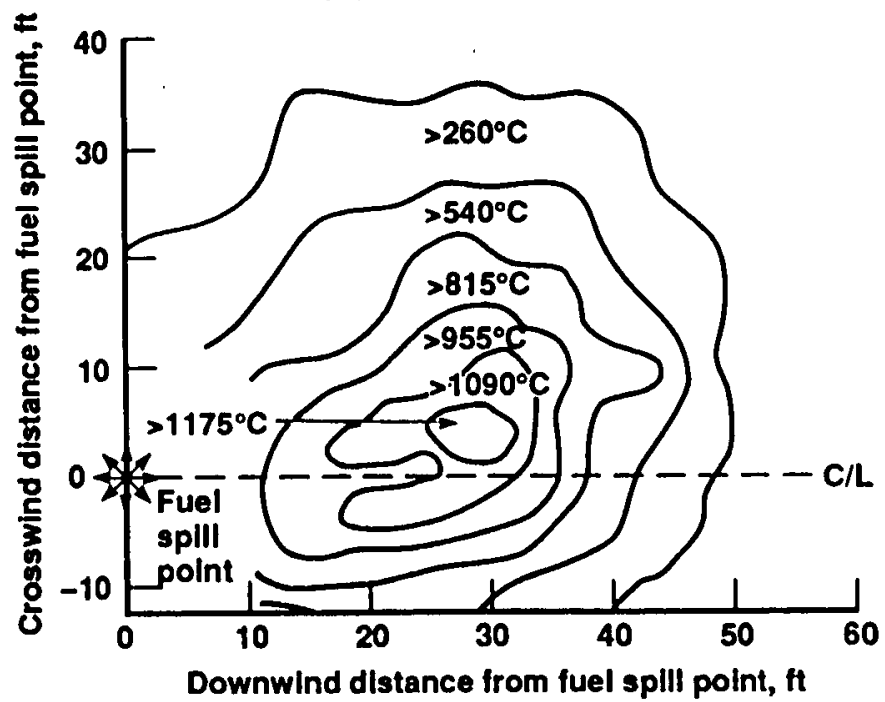

(d) 10-Foot height

Source: Mansfield (1991) 
Table 2. Probabilistic temperature distributions for spill fires, $\mathbf{3 0 0}$ gpm spill rate and mean wind velocities of $8 \mathrm{mph}$, as a function of height in fire (Mansfield, 1991).

$\mathbf{P}(\mathbf{T}>\mathbf{T})$

$\begin{array}{rlrrrc}\mathrm{T}^{\circ} \mathrm{C} & 1 \mathrm{ft} & 4 \mathrm{ft} & 7 \mathrm{ft} & 10 \mathrm{ft} & \begin{array}{c}\text { mean } \\ \text { all heights }\end{array} \\ 640 & 0.540 & 0.516 & 0.443 & 0.452 & 0.488 \\ 700 & 0.484 & 0.496 & 0.389 & 0.398 & 0.442 \\ 800 & 0.386 & 0.342 & 0.307 & 0.301 & 0.334 \\ 900 & 0.155 & 0.234 & 0.220 & 0.193 & 0.201 \\ 1000 & 0.0158 & 0.120 & 0.120 & 0.115 & 0.093 \\ 1050 & 0.0009 & 0.072 & 0.089 & 0.091 & 0.063 \\ 1100 & 0.0 & 0.037 & 0.057 & 0.062 & 0.039 \\ 1200 & 0.0 & 0 & 0.004 & 0.011 & 0.004\end{array}$


shown as a function of height in the fire. Thus, for each height, there is an equal probability that an object is within any area element of the fire. A mean distribution is also shown: in this case, there is an equal probability that an object is within any volume element of a fire.

It can be seen that temperatures are much lower at a height of $1 \mathrm{ft}$. and reach a maximum at heights of 7-10 ft. The distributions are for weighted wind speed probabilities for SAC bases, or about $8 \mathrm{mph}$, and for a spill rate of $300 \mathrm{gpm}$.

\section{Temperature probability distribution functions}

Results of these computations are shown in Fig. 5. My analysis of eleven pool fires 11 , that of Mansfield 25 for one pool fire (Table 3), and that of Mansfield 24 for spill fires are indicated on the figure.

\section{Relative $\mathrm{Pu}$ release probabilities}

We now use the results in Fig. 5 to compute the relative reduction in risk of $\mathrm{Pu}$ release by fire as a function of pit fire resistance. As an illustration we assume as a reference that a pit will release $\mathrm{Pu}$ to a fire as soon as it reaches a temperature equal to the melting point of $\mathrm{Pu}$; approximately $640^{\circ} \mathrm{C}$. It is noted that some pit designs might release liquid $\mathrm{Pu}$, or an alloy containing $\mathrm{Pu}$, at lower temperatures than this.

Then $\mathrm{PR}$, the relative $\mathrm{Pu}$ release probability of an FRP relative to a pit capable of $640^{\circ} \mathrm{C}$, can be computed for varying degrees of temperature resistance. These results for $\mathrm{PR}$ are plotted in Fig. 6 for the three volume-averaged temperature distributions and in Fig. 7 for the spill fire cases as a function of height in the fire. All curves show reductions in risk with increasing temperatures. Risk reductions become significant as temperature capabilities exceed $1000^{\circ} \mathrm{C}$. For $1 \mathrm{ft}$. heights, temperature resistances of $1100^{\circ} \mathrm{C}$ or more virtually preclude $\mathrm{Pu}$ release by fire, although at $10 \mathrm{ft}$. height the risk reduction is less than a factor of ten.

Risk reduction factors (IF) derived from all seven temperature distribution functions are shown in Table 4. Risk reduction factors for a given height can be used if the height is known or can be estimated for a given fire accident scenario.

For volume-averaged probabilities, or for equal probability of a pit within a fire, a FRP capable of $1000^{\circ} \mathrm{C}$ provides a risk reduction of 3-5, a FRP capable of $1100^{\circ} \mathrm{C}$ provides a risk reduction of $10-13$, and FRP resistance of $1200^{\circ} \mathrm{C}$ provides a risk reduction of about $120-300$. 
Table 3: Probabilistic temperature distributions for a pool fire (Mansfield, 1982).

$\begin{array}{rl}\mathrm{T}^{\circ} \mathrm{C} & \mathrm{P}(\mathrm{T}>\mathrm{T})) \\ 640 & 0.676 \\ 700 & 0.613 \\ 800 & 0.461 \\ 900 & 0.313 \\ 1000 & 0.161 \\ 1050 & 0.102 \\ 1100 & 0.066 \\ 1200 & 0.002\end{array}$




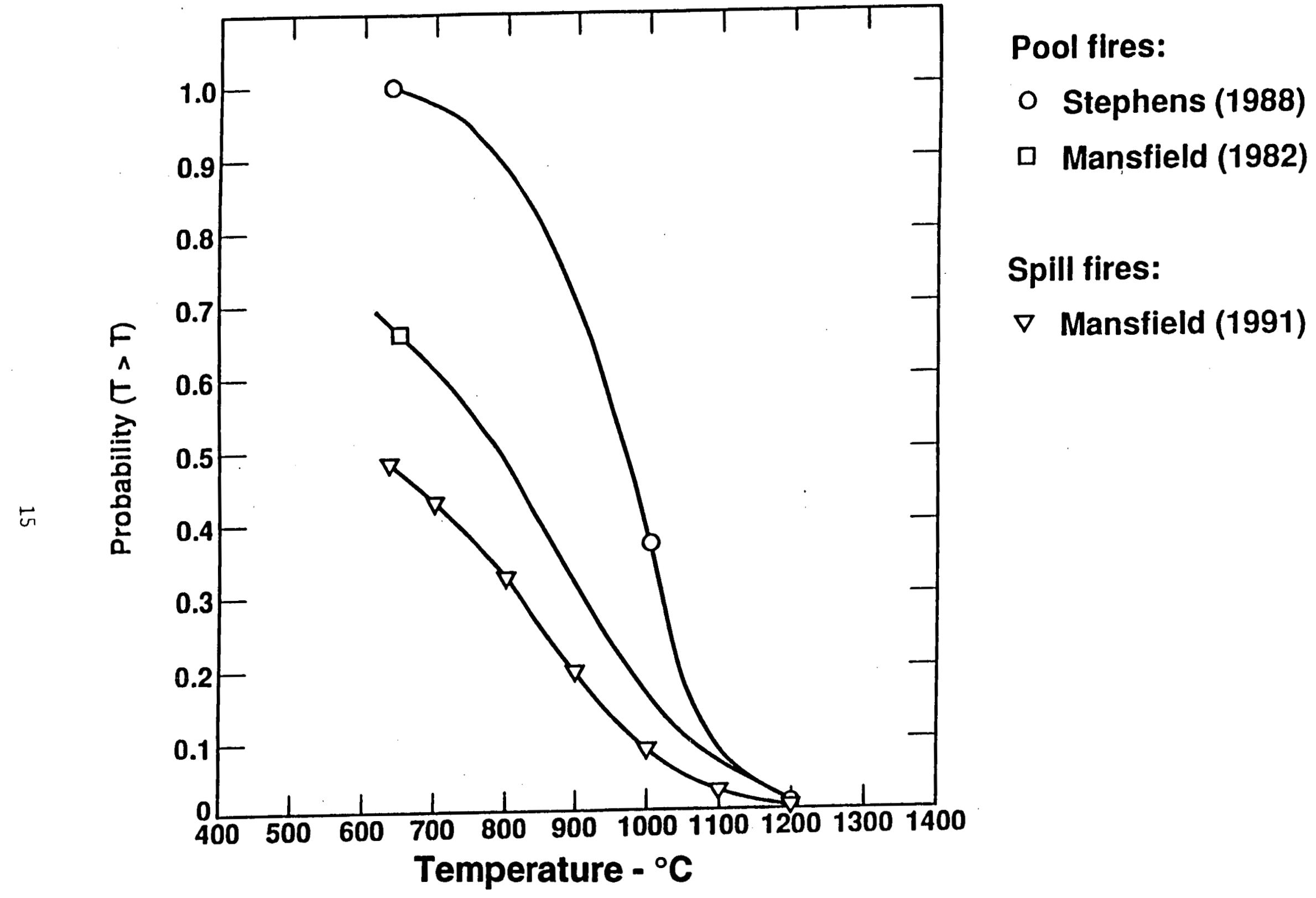

Figure 5: Free-field temperature probability distribution functions. There is an equal probability that an object is within any volume element of a fire. 


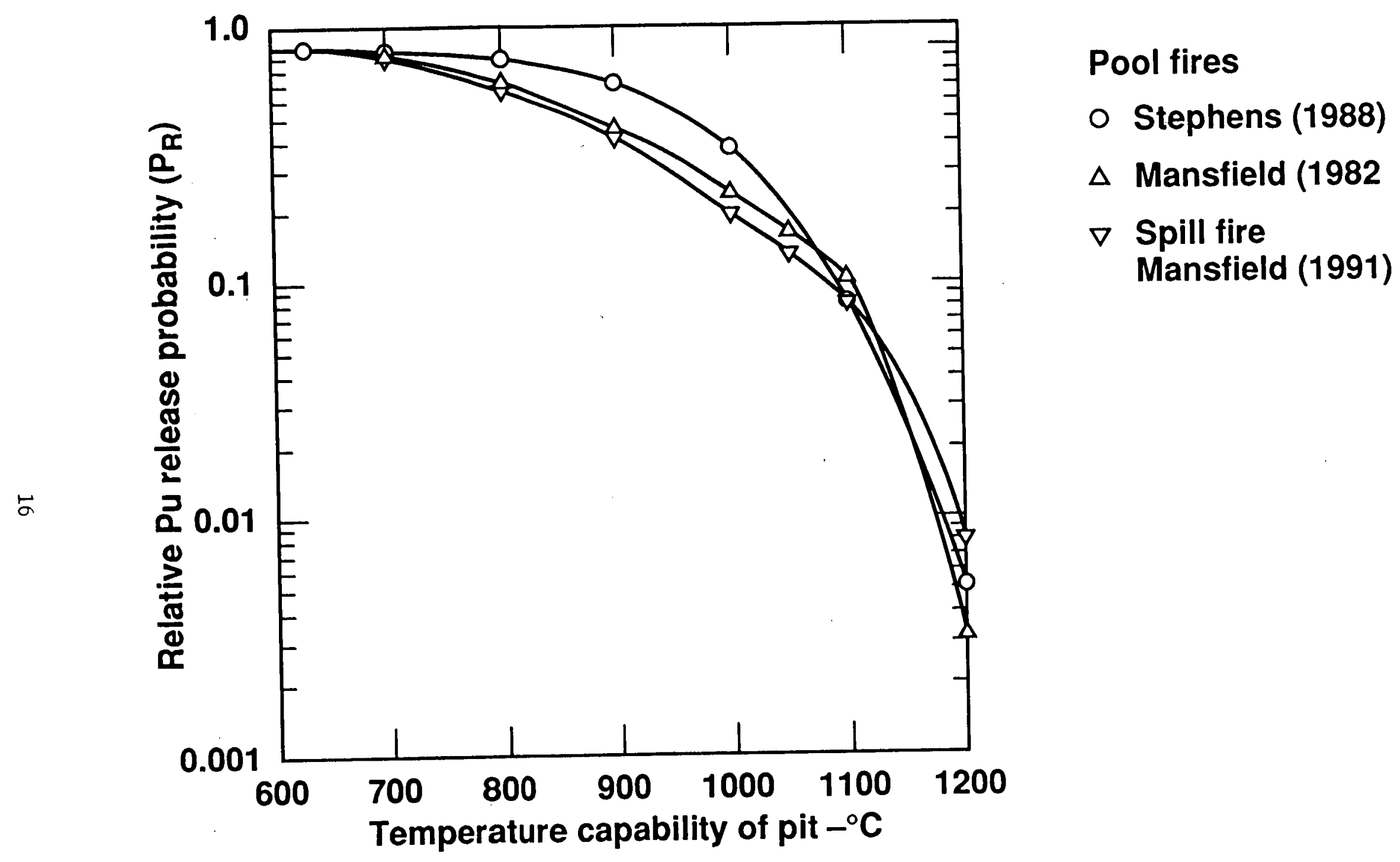

Figure 6: Relative Pu release probabilities normalized to $640^{\circ} \mathrm{C}$, as a function of temperature capability of a pit, for three volume-averaged temperature distribution functions. 


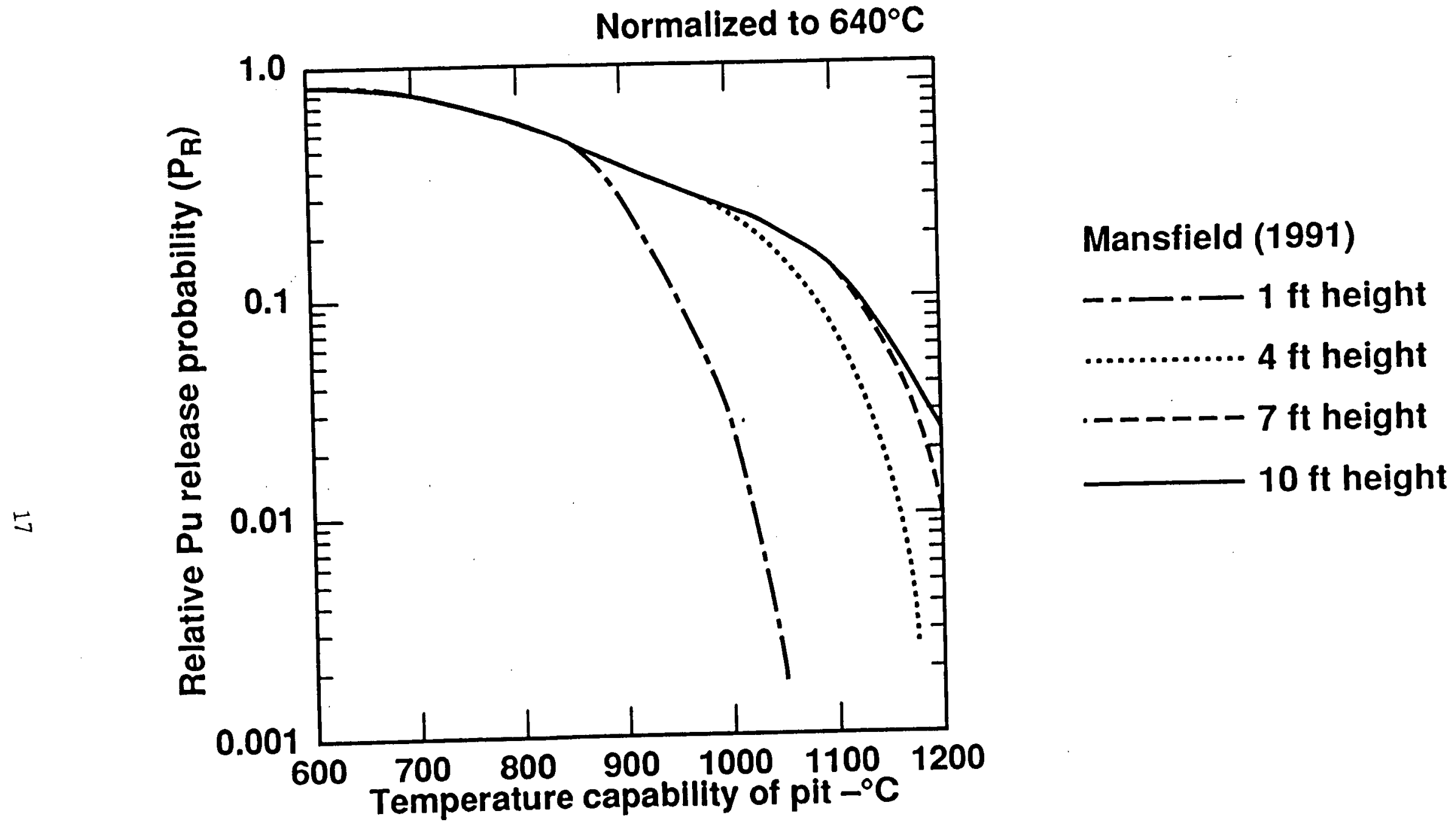

Figure 7: Relative Pu release probabilities normalized to $640^{\circ} \mathrm{C}$, as a function of temperature capability of a pit for spill fires. The spill rate is $300 \mathrm{gpm}$ and the weighted wind is $8 \mathrm{mph}$. Results are shown as a function of height in the fire. 
averaged by height in spill fires

volume-averaged temperature distributions Mansfield (1991)

Pit

Capability Stephens Mansfield Mansfield ${ }^{\circ} \mathrm{C}$

1000

2.7

12.5

200 (1982)

4.2

10.2

300

(1991)

5.2

12.5

120
$1 \mathrm{ft} . \quad 4 \mathrm{ft} . \quad 7 \mathrm{ft} . \quad 10 \mathrm{ft}$. height height height height

34

4.3

$3.7 \quad 3.9$

$\begin{array}{llll}\infty & 14 & 7.8 & 7.3\end{array}$

$\infty$

$\infty \quad 110$

41

TABLE 4. Risk reduction factors normalized to $640^{\circ} \mathrm{C}$, as a function of temperature capability of pit, for pool and spill fires. 


\section{Limitations}

Important caveats for this analysis include:

(1) The temperature distributions, relative $\mathrm{Pu}$ release probabilities and risk reduction factors were derived from free-field pool and spill fires. The presence of large objects, such as an aircraft fuselage is expected to alter the temperature distributions.

(2) The uncertainties within the temperature distributions themselves have not been quantitatively analyzed. This is recommended.

(3) Fuel fire durations were not addressed.

(4) Possible effects of oxygen (liquid or gas) were not addressed.

(5) Propellant fire effects, which can be a dominant effect in missile systems, were not considered.

(6) Effects of burning metal were not analyzed.

(7) Effects of weapon location were not addressed. It was assumed in all cases that the weapon was within the luminous plume of the fuel fire.

(8) The time-averaging was not varied but was fixed at two minutes.

(9) Combined accident environments such as impact followed by fire were not considered.

(10) Effects of HE burn, especially non-uniform HE burn, were not considered.

When propellant is present in the accident scenario, it must be considered on a system-specific basis as was done for Peacekeeper in Minuteman Silos ${ }^{26}$ where the effects of both a fuel and propellant fire were explicitly computed.

As stated earlier, it is difficult to include the potential effects of burning metal. Such an analysis is likely to be system-specific, while the analyses in this section are intended to be as system-independent as possible. 
The contributions of fuel fire duration and combined impact/fire environments to relative risks for $\mathrm{Pu}$ release by fire are discussed in the following two sections.

\section{Fuel fire durations}

Martin Fuentes 27 , in his study of military aircraft fire durations, found in the accident database many fires of a few minutes or less, few if any fires of durations of minutes to about an hour, and six aircraft fires of durations exceeding one hour. Although attempts were made to extinguish the fires, all six aircraft were destroyed. This suggests that, for military aircraft accidents, fire durations would be approximately constant for durations of 0.75 to 1.5 hours, which are of the most interest for our case.

Commercial aircraft fire durations, from R. Mensing 28 , are shown in Fig. 8. The durations are reasonably continuous but show a rather flat distribution between 0.75 and 1.5 hours. The decrease in that range is only about $10 \%$.

So from presently available data one does not expect much benefit from fire durations for relative risk reduction factors, for fire durations between 0.75 and 1.5 hours. (Of course the absolute risk is affected by duration density functions). Further examination of empirical fire data is recommended.

I am unaware of any credible fuel fire duration models. An early model ${ }^{16}$ assumed a pool fire, rather than a much more likely spill fire. The model further assumes that all the available fuel is spilled instantaneously into a pool equal in diameter to the dimensions of the aircraft and to a depth commensurate with that diameter and the volume of fuel. This model can lead to nonphysical results such as fuel pool diameters of 120-150 ft. and depths of 4-6 inches. It is difficult to visualize such a pool being stable on a smooth flat surface such as a runway.

A "first cut" fuel fire duration model is under development, which will include a fire temperature model (one or more of the previously described temperature distributions), a fire boundary model, a fuel consumption model, a tank rupture/fuel leak model, and finally a fire-fighting model 29 .

\section{Combined impact and fire accidents}

This analysis is based on the SRAM-A study8, using accident frequencies similar those determined in that assessment. My purpose is to illustrate the relative contributions of accident scenarios involving impact and fire to those involving fire alone. I assume a serious accident frequency (one with potential Pu release) of $3 \mathrm{X}$ 


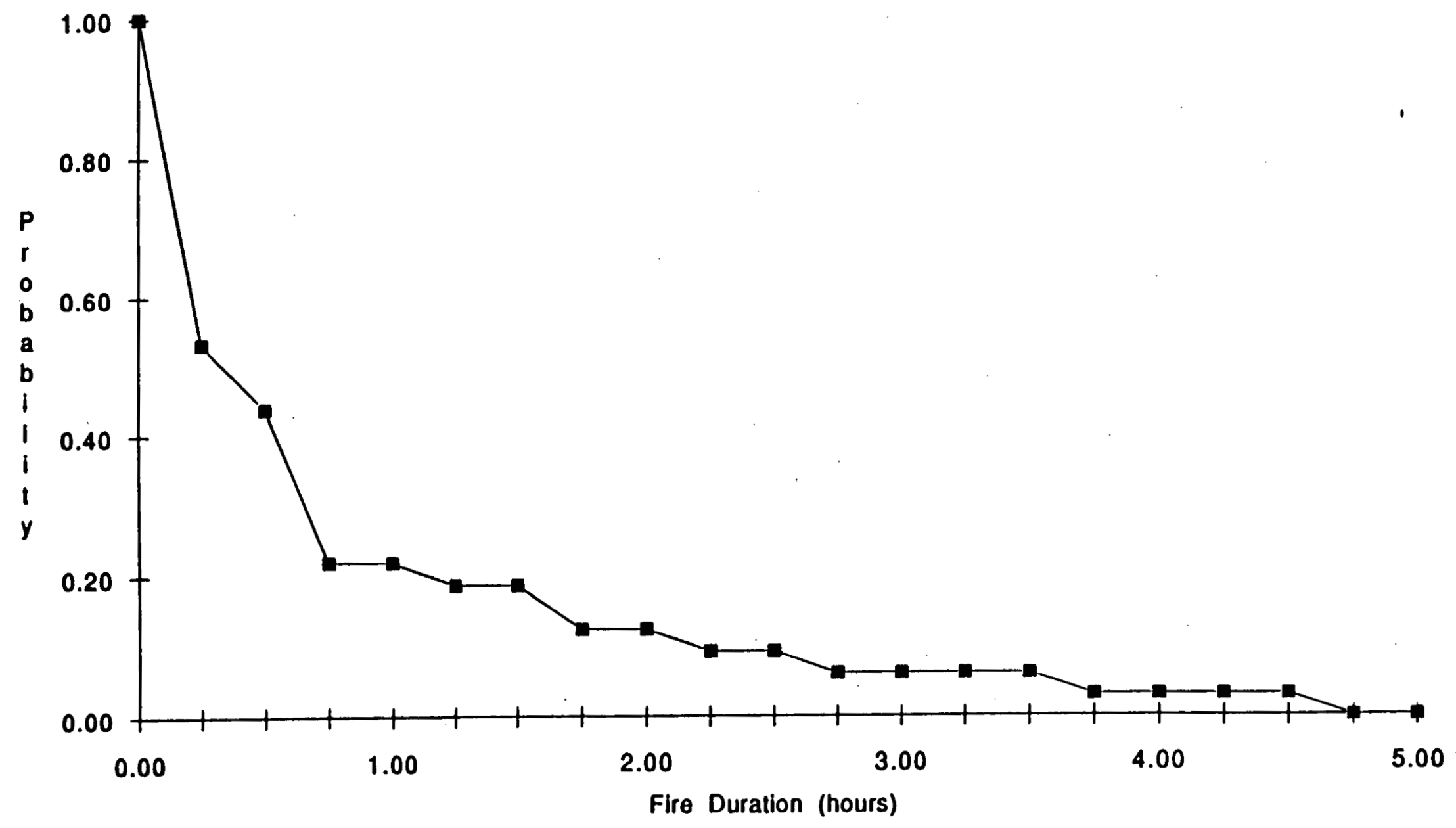

Figure 8: Commercial aircraft fire durations Source: R. Mensing (1991) 
$10^{-3}$, of which $2 / 3$ is due to fires without significant impacts and $1 / 3$ is due to aircraft crashes into alert bombers.

Two lumped accident scenarios are considered: an intact pit in a fire, and a pit which has been ruptured by a violent aircraft crash followed by involvement in the ensuing fire. I assume that all weapons contain IHE, so the probability of violent HE reaction can be neglected. I further assume that when an FRP's protective shells have been fractured by impact, Pu will be released at $640^{\circ} \mathrm{C}$, the melting point of plutonium.

The calculations are briefly outlined below.

$$
\mathrm{FPu}_{\mathrm{Pu}}=\mathrm{F}_{\mathrm{T}}+\mathrm{F}_{\mathrm{I}}
$$

where

$\mathrm{FPu}_{\mathrm{Pu}}=$ annual $\mathrm{Pu}$ release frequency

$\mathrm{F}_{\mathrm{T}}=$ annual $\mathrm{Pu}$ release frequency, due to temperature scenarios

$\mathrm{F}_{\mathrm{I}}$ = annual Pu release frequency, due to combined impact and temperature

$$
F_{T}=\sum F_{A F} P_{1} P_{2} P(T)
$$

where

$\mathrm{F}_{\mathrm{AF}}=$ accident frequency leading to fire

$P_{1}=$ probability of sufficient fire duration

$P_{2}=$ probability of weapon in fire

$\mathrm{P}(\mathrm{T})=$ probability of $\mathrm{T}>\mathrm{T}$, the temperature capability of the FRP.

$$
F_{I}=F_{A I} P_{1} P_{2} P(T)
$$

where

$\mathrm{F}_{\mathrm{AI}}=$ frequency of accidents leading to pit rupture followed by fire

In this case $P(T)=1.0$ 
let

$$
\begin{aligned}
& F_{A I}^{\prime}=F_{A I} P_{1} P_{2} \\
& F_{A F}^{\prime}=\Sigma F_{A F} P_{1} P_{2}
\end{aligned}
$$

then

$$
\begin{aligned}
\mathrm{F}_{\mathrm{Pu}} & =\mathrm{F}_{\mathrm{AF}} \mathrm{P}(\mathrm{T})+\mathrm{F}_{\mathrm{AI}} \\
& =2.8 \times 10^{-3} \text { for } \\
\mathrm{P}(\mathrm{T}) & \sim 1.0 \text { (modified from SRAM-A study) }
\end{aligned}
$$

I used an aircraft crash model ${ }^{30}$ to estimate the probabilities that an aircraft would impact the alert bomber at varying velocities. These results are shown in Table 5a, and the values of $F_{A I}$ and $F_{A F}$ are given in Table $5 b$ as a function of impact velocity. These calculations assume the pit would rupture due to an aircraft crash into the alert bomber at the velocities given in Table 5.

The results of these estimates are shown in Fig. 9 for systems at varying temperature and impact resistance. The three temperature distributions are those for equal probabilities that the pit is within any volume element of the fire.

The case of infinite impact resistance $\left(\mathrm{F}_{\mathrm{AI}}=0, \mathrm{~F}_{\mathrm{AF}}=2.8 \times 10^{-3} / \mathrm{y}\right)$ shows, of course, exactly the same risk reduction as for the fire temperature distributions. The answers are about the same for an impact resistance of $300 \mathrm{ft} / \mathrm{sec}$ until temperatures of about $1100^{\circ} \mathrm{C}$ are attained or exceeded. The lower impact resistance cases show much less risk reduction. All finite impact resistance cases approach a Pu release frequency of $\mathrm{F}_{\mathrm{AI}}$ at sufficiently high temperature capabilities: this is due to the violent impact scenario becoming dominant compared to fire resistance.

We conclude that impact resistance of a system may be important for FRPs. Designers need to incorporate strength as well as temperature resistance for systems which may experience accidents combining impact with fire. Of course, the exact ratio of impact/fire frequencies to those of fire alone will influence the amount of strength required. Further, a pit capable of withstanding an aircraft crash of a given velocity, say $300 \mathrm{ft} / \mathrm{sec}$, has a capability of a rigid wall impact far less than this. Mitigation of the aircraft structures, plus simple conservation of momentum arguments suggest a decrease of velocity to the warhead of a factor of two or more relative to the impacting aircraft velocity. The actual mitigation of fuselages, containers, etc. should be calculated, or better yet, measured to determine strength 
Table 5a: Aircraft crash probability

$\begin{array}{cc}\begin{array}{c}\text { Aircraft impact } \\ \text { velocity }\end{array} & \begin{array}{c}\text { Probability of } \\ \mathbf{v}>\mathbf{v}\end{array} \\ \mathrm{ft} / \mathrm{sec} & \\ 0 & 1.0 \\ 150 & 0.33 \\ 200 & 0.22 \\ 250 & 0.11 \\ 300 & 0.009\end{array}$

Table 5b: Values of $\mathrm{F}^{\prime} \mathrm{AI}=\mathrm{F}_{\mathrm{AF}} \mathrm{AF}$ with impact velocity $\begin{gathered}\text { Aircraft impact } \\ \text { velocity } \\ \mathrm{ft} / \mathrm{sec}\end{gathered}$
annual frequencies $\quad \begin{gathered}\mathrm{F}_{\mathrm{AI}} \\ \text { annual frequencies }\end{gathered}$

$\begin{array}{rrr}150 & 3.3 \times 10^{-4} & 2.47 \times 10^{-3} \\ 200 & 2.2 \times 10^{-4} & 2.58 \times 10^{-3} \\ 250 & 1.1 \times 10^{-4} & 2.69 \times 10^{-3} \\ 300 & 9 \times 10^{-6} & 2.79 \times 10^{-3}\end{array}$






Figure 9: Example fuel fire plutonium dispersal probabilities for SAC bases 
requirements. But the bottom line is that impact as well as temperature capabilities must be considered for an FRP.

\section{CONCLUSIONS}

(1) Improvements in FRP temperature capabilities, on a system-independent basis, lead to the following estimated reductions in risk, normalized to a temperature capability of $640^{\circ} \mathrm{C}$ (the melting point of plutonium):

$$
\begin{aligned}
& 1000^{\circ} \mathrm{C} \text { - factor of } 3 \text { to } 5 \\
& 1100^{\circ} \mathrm{C} \text { - factor of } 10 \text { to } 13 \\
& 1200^{\circ} \mathrm{C} \text {-factor of } 120 \text { to } 300
\end{aligned}
$$

The above values would, of course, vary for a different normalization temperature.

(2) The uncertainties in the above values are based upon three different temperature distributions. An uncertainty analysis of the basic temperature data is recommended.

(3) The effects of large perturbing objects altering the free-field fire data were not considered. Measurement of spill fire distributions with suitable perturbing objects is recommended.

(4) Incorporation of fuel fire duration distributions will increase the above FRP improvement factors. An in-depth study of military aircraft fire durations is recommended, as is development of a fire model.

(5) Systems incorporating propellants must be analyzed on a case-by-case basis. If significant, the FRP improvement factors may be reduced.

(6) Effects of burning HE, or possible sources of oxygen (other than air) were not considered. They would be analyzed on a system-specific basis. If significant, the above FRP improvement factors may be reduced.

(7) Effects of weapon location were not addressed.

(8) Time-averaging was held constant at two minutes.

(9) Analyses of combined impact/fire accidents show that the fracture resistance of the FRP is important above temperature capabilities of $1100^{\circ} \mathrm{C}$. 


\section{Acknowledgement}

I thank John Creighton, Edward Farley, James Hanafee, Hans Kruger, Ron Streit, George Thomas, Park Winter, LLL, and Martin K. Fuentes, SNL, for reviewing this report. 


\section{REFERENCES}

1. M.R. Madsen et al., Safety Assessment of ERDA Nuclear Weapon Transport Operations (U), Energy Research and Development Administration, Rept. ERDA-77/10, Vol. 1 (Basic Report) and Vol. 2 (Data and Calculations) (1977) (SRD).

2. W.H. Ling, Forward Look (U), Sandia National Laboratory, Albuquerque, Rept. SAND-79-1443 (RS-5611/79/154-172), Vol. $111 \mathrm{C}$ (1979) (SRD).

3. C.G. Shirley, Plutonium Dispersal Risk Analysis of Helicopter versus Truck Transport (U), Sandia National Laboratory, Albuquerque, Rept. RS-7233/86/028 (1986) (SRD).

4. C.G. Shirley and R.E. Smith, Plutonium Dispersal Probability Assessment for Weapon Storage Vaults in Hardened Aircraft Shelters (U), Sandia National Laboratory, Albuquerque, Rept. RS-7233/87/57 (1987) (SRD).

5. C.G. Shirley, Analysis of the Probability of Aircraft Crash into Areas of Concern at Site 110 (U), Sandia National Laboratory, Albuquerque (1987) (U).

6. R.E. Smith, Dispersal Risk Analysis of the H1501 in CH-47 Helicopter Severe Accidents (U), Sandia National Laboratory, Albuquerque, Rept. RS-7233/87/026 (1987) (SRD).

7. M.K. Fuentes and C.G. Shirley, Safety Assessment of IHE and Fire Resistant Pits in Abnormal Environments (U), Sandia National Laboratory, Albuquerque, Rept. RS-7233/89/00047 (1989) (SFRD).

8. SRAM-A Safety Study Report (U), OACD-91-0172, Vol. I - VII, (June 1991), (SRD).

9. DoD \& DOE study of Logistic Transportation of Nuclear Weapons (U). Vol. 1 thru 5B, September 1991. (SRD).

10. Trident II (D-5) Missile Accident or Incident Special Safety Review (U), U.S. Navy, Rept. OPNAV INST-S5513.5 (1986) (CNWDI).

11. D.R. Stephens, Plutonium Dispersal From Fuel Fires (U), LLNL Rept. UCID21489 (1988) (SRD). 
12. DOE Pilot Study, report in preparation.

13. W89 PRA, report in preparation.

14. Proposed Standard Method of Test of Effects of Large Hydrocarbon Pool Fires on Structural Members and Assemblies, Annual Book of ASTM Standards, Vol. 4.07, E-5 Proposal P 191, Appendix, 1254-1260 (1986).

15. J.J. Gregory, R. Mata Jr., N.R. Keltner, Thermal Measurements in a Series of Large Pool Fires, Sandia National Laboratories, Rept. SAND85-0196 (August 1987).

16. R.K. Clarke, J.T. Foley, W.F. Hartman, D.W. Larson Severities of Transportation Accidents, Sandia National Laboratories Rept. SLA-74-001 (July 1976).

17. B.E. Bader, Heat Transfer in Liquid Hydrocarbon Fuel Fires, Chemical Engineering Progress Symposium Series, Vol. 61, No. 56, 78-90 (1965).

18. M.E. Schneider and L.A. Kent, Measurements of Gas Velocities and Temperatures in a Large Open Pool Fire, Heat and Mass Transfer in Fire HTD-Vol. 73, 37-47 (1987).

19. L.H. Russell and J.A. Canfield, Experimental Measurement of Heat Transfer to a Cylinder Immersed in a Large Aviation - Fuel Fire, J. Heat Transfer, 25, 397404 (1973).

20. H.T. Johnson, L.J. Linley, and J.A. Mansfield, Measurement of the Spatial Dependence of Temperature and Gas and Soot Concentrations Within Large Open Hydrocarbon Fuel Fires, NASA Technical Memorandum 58230, JSC White Sands Test Facility, Las Cruces, NM (1982).

21. J. Creighton, Maximum, minimum and average temperatures experienced by objects with different thermal response times engulfed in a fire, LLNL memorandum (30 December 1991).

22. Joseph A. Mansfield, personal communication, December 5, 1991.

23. Joseph A. Mansfield and Larry J. Linley, Measurement and Statistical Analysis of Flame Temperatures from Large Fuel Spill Fires, Naval Weapons Center Report NWCTP 7061 (January 1991). 
24. Joseph A. Mansfield, in preparation.

25. Joseph A. Mansfield, 1982, quoted in reference 14.

26. Robert V. Homsy et. al., Plutonium Release Probabilities and Consequences for Peacekeeper in Minuteman Silos (PIMS), report DDV-91-0031, in preparation.

27. Martin K. Fuentes, Probability Assessment of Plutonium Dispersal from the W69/SRAM-A (U) Sandia National Laboratory, Rept. RS7233/90/00077, (July $11,1990)$. (SFRD).

28. J. H. Van Sant et. al., Plutonium Air Transport Certification (PATC) Program, Phase One Final Report, Project 1: Development of Criteria for Controlled Tests for Air Transport Packages, LLNL Rept. No. UCRL-ID-104484 (September 28, 1990).

29. D. Magnoli, W. Stein, and J. Creighton. in process.

30. R.E. Smith, A Methodology for Calculation of the Probability of Crash of an Aircraft into Structures in Weapon Storage Areas (U), Sandia National Laboratory, Albuquerque, Rept. SAND-82-2409 (1983) (U). 